\title{
Mindfulness and Romantic Relationship Outcomes: the Mediating Role of Conflict Resolution Styles and Closeness
}

\author{
Nathalie Gesell ${ }^{1}$ (D) $\cdot$ Frank Niklas $^{1} \cdot$ Sandra Schmiedeler $^{1} \cdot$ Robin Segerer $^{2}$ \\ Published online: 25 July 2020 \\ (C) The Author(s) 2020
}

\begin{abstract}
Objectives The association of mindfulness and romantic relationship outcomes such as partnership quality and satisfaction is well-established; however, the mechanisms of action are not yet clear. The current study tested conflict resolution styles and closeness as possible mediating factors. We hypothesized that trait mindfulness would increase the use of constructive conflict resolution styles (positive problem solving), decrease the use of destructive styles (conflict engagement, withdrawal, and compliance), and promote feelings of closeness between partners, which in turn would predict positive relationship outcomes (namely partnership quality, partnership satisfaction, and sexual satisfaction).

Methods A total of 209 individuals $(86 \%$ German, $76 \%$ female, mean age $=32$ years) living in a relationship $(31 \%$ married) participated in an online questionnaire.

Results Mediation analyses revealed that positive problem solving mediated the association between mindfulness and partnership quality with $b=.09(95 \% \mathrm{CI}=.03-.17)$, mindfulness and partnership satisfaction with $b=.07(95 \% \mathrm{CI}=.02-.13)$, and mindfulness and sexual satisfaction with $b=.04(95 \% \mathrm{CI}=.00-.10)$. Furthermore, a mediating role of withdrawal and closeness was shown for individual relationship outcomes.

Conclusions Findings suggest that more positive problem solving, less withdrawal, and more closeness are mechanisms by which mindfulness is associated with positive relationship outcomes. The results of our study thus broaden our understanding of the processes that underlie fulfilling romantic relationships and, in turn, underline the positive effects of mindfulness.
\end{abstract}

Keywords Mindfulness $\cdot$ Trait mindfulness $\cdot$ Romantic relationship $\cdot$ Relationship satisfaction $\cdot$ Closeness $\cdot$ Conflict resolution

Mindfulness is commonly defined as intentionally focusing one's attention on the present moment in a non-judgmental attitude (Kabat-Zinn 2009). Research has found mindfulness to be related to many positive psychological outcomes such as greater wellbeing or less emotional reactivity (for review, see Keng et al. 2011). One research field that has been attracting much interest in recent years is the relation of mindfulness with romantic relationship outcomes such as partnership quality and satisfaction as well as sexual satisfaction (for a review, see Atkinson 2013). Partnership satisfaction is defined as the

Nathalie Gesell

Nathalie.Gesell@gmx.de

1 Department of Psychology, University of Würzburg, Röntgenring 10, 97070 Würzburg, Germany

2 Department of Psychology, University of Basel, Missionsstraße 60/ 62, 4055 Basel, Switzerland subjective evaluation of one's own intimate relationship (Dinkel \& Balck 2005), whereas partnership quality refers primarily to behaviors that contribute to satisfaction such as a high proportion of shared experiences and high affective involvement of the partners (Kliem et al. 2012). In terms of romantic relationships, sexuality is another important aspect (Muise et al. 2016). Relationship satisfaction and sexual satisfaction are strongly associated (e.g., Byers 2005; SánchezFuentes et al. 2014), and sexual satisfaction is predictive for the development of marital quality and marital stability (Yeh et al. 2006).

Previous studies have tried to identify interpersonal processes that are associated with positive relationship outcomes. For instance, a secure attachment style, improved emotional self-regulation, more acceptance for oneself and one's partner, more empathy, more enjoyment of joint activities, greater perceived partner responsiveness, and actual and perceived relationship effort of a couple can predict partnership quality (e.g., Adair et al. 2018a; Pepping and Halford 2016; Shafer 
et al. 2014). An interactional model for the classification of behaviors in partnerships suggests two dimensions relevant to couple relationships: These are conflict behavior (constructive vs. destructive) and closeness (high vs. low) (Fruzzetti 1996). Research on individual and couple problems usually focuses on destructive conflict resolution styles such as conflict engagement only. However, a well-functioning relationship is not merely characterized by the absence of destructive conflict behavior; rather, a combination of constructive conflict behavior with a high degree of intimacy is a suitable definition for a well-functioning relationship (Fruzzetti 1996).

Conflict behavior has been proven to have a significant impact on the quality of and contentment with the partnership and how quality and contentment change (Askari et al. 2012; Gottman 2014; Kurdek 1995; Schneewind and Gerhard 2002; Segrin et al. 2009). By behavioral observations, four different conflict resolution styles were identified (Kurdek 1994): Positive problem solving describes behaviors such as talking calmly about the problem and making compromises. Conflict engagement is characterized by attacking the partner personally or losing control while arguing. Withdrawal includes behaviors such as disregarding the partner and showing no interest in the discussion, and compliance refers to not defending one's own position and personal interests. The frequent use of the destructive strategies conflict engagement, withdrawal, and compliance is associated with less partnership satisfaction, a more negative partnership development, and more frequent divorces, whereas a focus on positive problem solving is associated with greater relationship satisfaction and positive development (Kurdek 1994; Scheeren et al. 2014). In line with these findings, studies demonstrated that relationship satisfaction correlated negatively with aggression (Wachs and Cordova 2007), negative escalation, and criticism (Stanley et al. 2002). However, affective communication (i.e., feeling taken seriously and loved) and problem solving communication (i.e., the way in which problems are dealt with) have been shown to be the best individual predictors of marital satisfaction (Snyder 1979). In addition, several studies have linked sexual dysfunction to poor conflict resolution behavior (Chesney et al. 1981; Metz and Epstein 2002; Rosenheim and Neumann 1981; Schenk et al. 1983).

A second important determinant of partnership outcomes is closeness. The self-expansion model of close relationships (Aron and Aron 1986) states that people strive for selfexpansion by entering relationships in which the partner is incorporated into the self. Based on this model, interpersonal closeness is conceptualized as the amount of inclusion of the other in the self (IOS). The expanded self thus leads to a blurring of the boundaries between one's self and the other and can explain selfless behavior in close relationships (Aron et al. 1991). Helping the partner can be regarded as helping oneself (Aron et al. 2013). Closeness consists of emotional and behavioral aspects (Fruzzetti and Jacobson 1990), and closeness as IOS refers to both. Consequently, IOS is a suitable operationalization of this construct. Intimacy and closeness are considered the key benefits in a relationship (Fruzzetti and Iverson 2004). Closeness correlates positively with relationship quality and satisfaction (Agnew et al. 2004; Crespo et al. 2008; Cropley and Reid 2008; Weidler and Clark 2011). A meta-analysis that included 19 studies (Le et al. 2010) showed that a higher closeness score is associated with a lower probability of separation, with an effect size of Cohen's $d=$ -.70 . Whereas several studies analyzed the relationship between interpersonal closeness and relationship satisfaction, less attention has been paid to the connection between closeness and sexual satisfaction. Here, increasing closeness seems to increase the likelihood of having sexual intercourse and predicts greater sexual satisfaction (Rubin and Campbell 2012). In addition, associations between closeness in the relationship and sexual dysfunction were found (McCabe 1997). While studies consistently demonstrate the association between conflict behavior and closeness with various relationship outcomes, it is not yet clear whether these factors also mediate the relation between mindfulness and relationship outcomes.

Numerous studies have shown mindfulness to correlate positively with relationship outcomes such as partnership quality and one's own and the partner's satisfaction in marital and non-marital relations (Barnes et al. 2007; Burpee and Langer 2005; Iida and Shapiro 2017; Lenger et al. 2017; Wachs and Cordova 2007). For instance, trait mindfulness measured with the Mindful Attention Awareness Scale (MAAS) was positively associated with relationship satisfaction assessed with the Dyadic Adjustment Scale (Barnes et al. 2007; Wachs and Cordova 2007). In addition to such correlative studies, the results of at least one experimental training study also support the impact of mindfulness on relationship outcomes (Carson et al. 2004). Qualitative research suggests that mindfulness and meditation change one's own experiences, which in turn leads to positive changes in the relationship with others (Bihari and Mullan 2014; Pruitt and McCollum 2010). Only a few recent studies have investigated the association of trait mindfulness and sexual satisfaction showing positive correlations between both constructs (Khaddouma et al. 2015; Newcombe and Weaver 2016; Pepping et al. 2018). Former studies have primarily focused on clinical samples: Several studies have shown that mindfulness interventions improve aspects of sexuality such as sexual desire and arousal and the number of orgasms in persons with gynecologic cancer (Brotto et al. 2012a), in people reporting low sexual desire and impaired arousal (Brotto and Basson 2014; Paterson et al. 2017), in persons with sexual distress who have experienced sexual abuse in childhood (Brotto et al. 2012b), and in women suffering from provoked vestibulodynia (Brotto et al. 2013). Participants agreed that the mindfulness component was the most valuable part of 
such interventions (Brotto and Heiman 2007). The aspects of sexual functioning that have been analyzed in these studies such as low sexual interest or lack of orgasm are associated with sexual satisfaction (Smith et al. 2012).

Thus, whereas the association of mindfulness and romantic relationship outcomes are well-established, the mechanisms of action are not yet clear. Some findings might suggest that this connection is mediated by less destructive and more favorable conflict resolution strategies in mindful individuals. Mindfulness as a trait seems to be associated with more selfcontrol and less conflict engagement during a relationship dispute (Barnes et al. 2007) and less verbal defensiveness (Lakey et al. 2008) as well as with less dispositional aggression and hostile attribution bias (Burpee and Langer 2005; Kelley and Lambert 2012; Wachs and Cordova 2007). Furthermore, the association between a couple's mindfulness (mean of both partners' scores) and relationship quality seems to be fully mediated by the partners' skills to deal with anger (Wachs and Cordova 2007). The authors concluded that less mindfulness leads to destructive conflict solving strategies affecting relationships in a detrimental way. However, this research focused on destructive conflict resolution strategies only, whereas constructive processes such as positive problem solving had not been taken into account. Qualitative research revealed that participants of a mindfulness-based cognitive therapy felt that they could deal better with relationship conflicts by stopping and stepping back and, in turn, reacting more mindfully and constructively instead of automatically (Bihari and Mullan 2014). In addition, an acceptance-based couple therapy showed improved communication skills compared with a change-based intervention (Cordova et al. 1998). In sum, there is evidence that mindfulness is also related to more constructive conflict resolution skills, which in turn are crucial for relationship satisfaction.

Mindfulness is also associated with interpersonal closeness. Couples who had participated in the mindfulness-based relationship enhancement program (MBRE; Carson et al. 2004) had significantly higher closeness scores (as measured by the IOS) than the control group. A recent experimental study found that gains in trait mindfulness predicted increased feelings of social connection (Adair et al. 2018b). The authors assumed that mindfulness enables people to be both, more present during interactions as well as less self-focused, which fosters feelings of closeness. In line with these findings, mindfulness also predicted perceived social connection during interactions with the romantic partner (Quaglia et al. 2015). This association also applies to other types of relationships: Dispositional mindfulness in teachers was associated with closeness to their students (Becker et al. 2017). In addition, mindfulness meditation (a technique that can train trait mindfulness) reduced self-centeredness which in turn enabled a greater self-other connectedness (Trautwein et al. 2014). Looking at brain activity suggests a connection of mindfulness and interpersonal closeness: Meditation was associated with smaller differences between self- and otherrelated event-related potential components, indicating a stronger self-other integration (Trautwein et al. 2016). Furthermore, dispositional mindfulness correlated negatively with activity in self-referential brain areas (Way et al. 2010). Consequently, there are indications for mindfulness to be related to more interpersonal closeness, in general, and, specifically, in romantic relationships, which in turn might be also associated with positive relationship outcomes.

The aim of the present study is to investigate if conflict solving strategies and closeness function as mediators in the relation between mindfulness and romantic relationship outcomes (partnership quality, partnership satisfaction, and sexual satisfaction). Based on past findings, we hypothesized that the association between mindfulness and relationship satisfaction is mediated (H1) not only through destructive conflict resolution styles like conflict engagement, withdrawal, and compliance but also (H2) through positive problem solving and (H3) through interpersonal closeness.

\section{Methods}

\section{Participants}

The main inclusion criteria for participants were to be living in a dyadic relationship at the time of the survey and to fill-in all questionnaires relevant to the survey. In a bias-corrected bootstrap test of mediation, conventional linear power analyses cannot be applied (MacKinnon et al. 2004). Necessary power depends on a multitude of particulars of the data and the theoretical underpinnings of the study. Given the novelty of our research questions and the statistical method, we must rely on sample sizes in similar studies. The results of a literature survey show that the median sample size for the study of mediation hypotheses is about $n=183$ (Fritz and MacKinnon 2007). In our study, 209 women and men ( $75.6 \%$ female) participated of whom $85.6 \%$ were German and $14.4 \%$ had an immigrant background (i.e., at least one foreign-born parent). The majority of the sample $(n=202)$ was heterosexual, 4 were homosexual, and 3 did not classify themselves into these categories. The average age of participants was approximately 32 years $(M=32.2, S D=11.6$, range $=18$ to 78$)$. Participants were predominately highly educated $(57.9 \%$ university degree, $27.3 \%$ high school, $4.8 \%$ vocational diploma, $6.2 \%$ vocational training, $2.4 \%$ secondary school, $1.4 \%$ other). $23.9 \%$ reported having any experience with mindfulness practices. The average duration of the current partnership was 8 years ( $S D=9.6$, range $=2$ months to 47.4 years). $30.6 \%$ were married and $28.2 \%$ had at least one child. Even though a 2-month relationship duration seems quite short, the authors decided not to set a random lower limit as the mere relationship length 
need not necessarily reflect the relationships' stage (Acker and Davis 1992).

\section{Procedures}

The present study was part of a larger research project. The tool SoSci was implemented to develop an online survey composed of different questionnaires and to recruit the largest possible number of participants. The survey link was disseminated via various social networks, by e-mail distribution lists of university departments, and via private contacts. The target group consisted of persons who were living in a relationship at the time of the survey. As an incentive for participation, participants were given the chance to win one of various vouchers. On average, participants required about $30 \mathrm{~min}$ to complete the survey.

\section{Measures}

Mindfulness Trait mindfulness was measured using the German version of the MAAS (Michalak et al. 2008). The 15-item questionnaire is an economic, reliable, and valid instrument with good internal consistency of $\alpha=.83$ (Michalak et al. 2008) and $\alpha=.89$ (MacKillop and Anderson 2007). The items describe behaviors that reflect a mindless attitude, such as "I rush through activities without being really attentive to them," which participants rated on a 6-point Likert scale $(1=$ almost always, $6=$ almost never) considering their behavior in everyday life. The mean of the item values is calculated with higher values reflecting a higher level of mindfulness. In the present sample, internal consistency of $\alpha=.88$ was found. The MAAS is the most commonly used mindfulness measure (Medvedev et al. 2016), which operationalizes mindfulness as a naturally occurring trait and is explicitly applicable to participants not trained in meditation (Bergomi et al. 2013).

Conflict Resolution Styles The Conflict Resolution Style Inventory for Couples (CRSI; Kurdek 1994; German version by Herzberg and Sierau 2010) assesses four different coping styles: conflict engagement, positive problem solving, withdrawal, and compliance, with 4 items representing each style. To keep the survey as short as possible for the participants, the item with the lowest discriminatory power/factor loading of each subscale was omitted, reducing the total number to 12 items. Participants were asked to indicate on a 5-point Likert scale $(1=$ never, $5=$ always $)$ how often they show the respective behavior in a dispute situation with the partner. All subscales had acceptable reliability scores in our sample $(\alpha=.70-.79)$.

Inclusion of Other in the Self The Inclusion of Other in the Self Scale (IOS; Aron et al. 1992) works with a visualization of two circles representing both partners, which gradually overlap each other more or less. Subjects should select from seven levels the image that best reflects the relationship with the partner, with a larger overlap standing for more closeness in the relationship. The scale relates to both factors of closeness: (1) feelings of closeness and (2) actions associated with closeness. This suggests that the IOS scale addresses the core meaning of closeness, which is the sense of being interconnected, rather than just one aspect of it (Aron et al. 2013). The sense of interconnectedness may result from both conscious and unconscious processes (Aron et al. 1992). Studies show that this scale is an economic and easily understood measure of closeness in romantic relationships (Gächter et al. 2015) with reasonable reliability and validity and that is not prone to bias due to social desirability (Aron et al. 1992).

Partnership Quality To assess the quality of the partnership as determined by concrete behaviors, the short form of the partnership questionnaire (PFB-K; Kliem et al. 2012) was used, which was developed based on the partnership questionnaire by Hahlweg (1996). Here, the dimensions togetherness (e.g., talking to each other for at least half an hour each day), tenderness (e.g., stroking each other tenderly), and quarreling (e.g., feeling criticized in a sarcastic way) are distinguished with each dimension being represented by three items. As the conflict resolution styles already cover quarreling, only the scales togetherness and tenderness were used for the mediation analyses in our study. Participants were asked to indicate on a 4-point Likert scale ( 1 = never/very rarely, $4=$ very often $)$ how often the described behaviors have occurred in their relationship in recent times. A sum value was formed for each subscale, and in addition, a total score for the PFB-K was calculated. The questionnaire has a satisfactory internal consistency of $\alpha=.84$ and represents an economic and reliable instrument for measuring the quality of the partnership (Kliem et al. 2012), which was also confirmed in our sample with $\alpha=.87$ (subscales $\alpha=.71-.89$ ).

Partnership Satisfaction The German version of the Relationship Assessment Scale (RAS; Hendrick 1988) was used to measure the emotional aspects of relationship satisfaction, representing an overall evaluation of the partnership (e.g., "how much do you love your partner?", "how well does your partner meet your needs?"). Respondents rated each of seven items on a 5-point Likert scale (e.g., very bad-very good, very satisfied-very dissatisfied). The mean value of the items was calculated, and a greater value indicated greater relationship satisfaction. This measure is an economical, reliable, and valid measuring instrument with a high internal consistency ( $\alpha=.89$; Dinkel and Balck 2005). In our sample, excellent internal consistency of $\alpha=.90$ was found.

Sexual Satisfaction Based on a single-item measure tested by Mark et al. (2014), global sexual satisfaction was captured by 
a single item ("How satisfied are you generally with your sexual relationship with your partner?"), which participants should rate on a 5 -point Likert scale $(1=$ very unhappy, $5=$ very happy). The single-item scale demonstrated convergent validity and retest reliability (Mark et al. 2014). A single-item measure was preferred over a longer measure for its economy and as more detailed questions about sex life might be too shameful for an online survey.

\section{Data Analyses}

Data were analyzed using IBM SPSS Statistics 24. In a first step, descriptive statistics and partial correlations of all study variables were calculated, controlling for age, sex, education, immigrant background, relationship duration, marriage, and children, as those have been shown to be associated to our outcome variables (e.g., Heiman et al. 2011; Jose and Alfons 2007; Twenge et al. 2003). To test the mediation hypotheses, the SPSS macro PROCESS by Hayes (2013) was used. This approach allows the examination of multiple mediation models in which multiple mediators can be tested simultaneously. It has some advantages over testing multiple simple mediation models. Not only is it possible to test whether a variable functions as a mediator, but it is also possible to check to what extent this variable remains significant in the model taking into account the other mediators. Consequently, the magnitudes of the indirect effects can be considered in comparison (Preacher and Hayes 2008).

In pre-analyses, the PFB-K including the subscales as well as the RAS showed a negatively skewed distribution. By squaring, an approximation to the normal distribution was achieved. The analyses were performed using the transformed data. Further assumptions such as homoscedasticity, independence, and normal distribution of the error values were given. To obtain standardized coefficients, all variables were $z$-standardized. Significance checks were conducted by bootstrapping, using bias-corrected $95 \%$ confidence intervals. Here, the number of samples taken from the original sample was set at 10,000 each.

\section{Results}

Table 1 shows the partial correlations, means, standard deviations, and Cronbach's alpha coefficients of all variables.

As assumed, significant correlations of mindfulness with partnership satisfaction (RAS, $p<.01$ ), partnership quality (PFB-K, $p<.01)$, and sexual satisfaction $(p<.01)$ were found. Furthermore, as expected, constructive conflict resolution was positively associated and destructive conflict resolution was negatively associated with the indicators of relationship satisfaction. The destructive styles conflict engagement, withdrawal, and compliance showed significantly negative correlations with the RAS $(p<.01)$ and the scales togetherness and tenderness of the PFB-K $(p<.01)$. In addition, sexual satisfaction was negatively associated with withdrawal and compliance. In contrast, positive problem solving showed significantly positive associations with sexual satisfaction $(p<.05)$ and all other indicators of relationship satisfaction $(p<.01)$. In line with our assumptions, mindfulness correlated positively with positive problem solving $(p<.01)$ and negatively with withdrawal $(p<.05)$ and compliance $(p<.01)$. Only for conflict engagement, no significant correlation was found. Finally, IOS showed significant correlations with RAS and PFB-K, including all subscales $(p<.01)$, and a significant association with sexual satisfaction $(p<.05)$. In addition, a significant correlation between mindfulness and IOS $(p<.05)$ was found.

The final model that tested the mediation between mindfulness and partnership quality (sum of togetherness and tenderness of the PFB-K) was significant with $F$ (6 202) = $21.87, p<.001$, and the predictors explained about $39.4 \%$ of the variance of partnership quality. After including the possible mediating variables, no significant direct effect of mindfulness on partnership quality was found. In the confidence interval of the total indirect effect, the value 0 is not included; thus, mediation can be assumed, $b=.15(95 \% \mathrm{CI}=.05-.24)$. A significant indirect effect of mindfulness on partnership quality mediated through positive problem solving, $b=.09$ $(95 \% \mathrm{CI}=.03-.17)$ was found. The indirect effects via the other conflict resolution styles were not significant. For the mediated effect by IOS, 0 was not included in the $95 \%$ confidence interval, $b=.03$ (95\% CI $=.00-.08)$. Figure 1 shows the standardized b-coefficients of each path.

The final model for the association between mindfulness and partnership satisfaction (RAS) was significant, $F$ (6 202) $=32.74, p<.001$, and $49.3 \%$ of the criterion variance was explained by the predictors. A significant total effect and significant indirect effects mediated through positive problem solving $b=.07(95 \% \mathrm{CI}=.02-.13)$ and withdrawal $b=.02$ $(95 \% \mathrm{CI}=.00-.06)$ were found, whereas for IOS, only a non-significant tendency was found $b=.05(95 \% \mathrm{CI}=$ $-.00-.11)$. In the final model with all possible mediators in the model, no significant direct effect of mindfulness on partner satisfaction was found (see Fig. 1).

The final model for the association between mindfulness and sexual satisfaction was significant, $F(6$ 202) $=4.17$, $p<.001$, and about $11 \%$ of the criterion variance was explained by the predictors. There was a significant total indirect effect of mindfulness on sexual satisfaction with $b=.07$ (95\% $\mathrm{CI}=.01-.14)$. The effect was mediated by positive problem solving with $b=.04(95 \% \mathrm{CI}=.00-.10)$ and withdrawal with $b=.02(95 \% \mathrm{CI}=.00-.06)$. Again, there was a non-significant tendency for the mediating effect of $\operatorname{IOS} b=.01(95 \% \mathrm{CI}=$ $-.00-.05)$. In the final model with all possible mediators included, there was no significant direct effect of mindfulness on sexual satisfaction (see Fig. 1). 
Table 1 Partial correlations, means, standard deviations, and internal consistencies of the study variables $(N=209)$

\begin{tabular}{|c|c|c|c|c|c|c|c|c|c|c|c|c|c|c|}
\hline & 2 & 3 & 4 & 5 & 6 & 7 & 8 & 9 & 10 & 11 & 12 & $M$ & $S D$ & $\alpha$ \\
\hline 1 MAAS & -.11 & $.21 * *$ & $-.17 *$ & $-.29 * *$ & $.13^{*}$ & $.26^{* *}$ & $.29 * *$ & $.26^{* *}$ & $.25^{* *}$ & $.21 * *$ & $.19 * *$ & 4.09 & .75 & .88 \\
\hline 2 CRSI conflict eng. & - & $-.51 * *$ & $.25 * *$ & -.00 & $-.22 * *$ & $-.34 * *$ & $-.31 * *$ & $-.32 * *$ & $-.25 * *$ & $-.19 * *$ & -.03 & 2.00 & .83 & .79 \\
\hline 3 CRSI positive prob.sol. & & - & $-.38 * *$ & $-.17 *$ & $.31 * *$ & $.53 * *$ & $.54 * *$ & $.40 * *$ & $.49 * *$ & $.44 * *$ & $.18^{*}$ & 3.98 & .63 & .70 \\
\hline 4 CRSI withdrawal & & & - & $.23 * *$ & $-.20 * *$ & $-.38 * *$ & $-.29 * *$ & $-.28 * *$ & $-.26^{* *}$ & $-.18 * *$ & $-.19 * *$ & 2.13 & .84 & .74 \\
\hline 5 CRSI compliance & & & & - & -.11 & $-.20 * *$ & $-.25^{* *}$ & $-.24 * *$ & $-.21 * *$ & $-.16^{* *}$ & $-.11 *$ & 2.23 & .80 & .77 \\
\hline $6 \mathrm{IOS}$ & & & & & - & $.53 * *$ & $.39 * *$ & $.22 * *$ & $.40 * *$ & $.35^{* *}$ & $.15^{*}$ & 4.84 & 1.42 & \\
\hline 7 RAS & & & & & & - & $.74 * *$ & $.50 * *$ & $.69 * *$ & $.63 * *$ & $.45^{* *}$ & 4.22 & .71 & .90 \\
\hline 8 PFB-K total & & & & & & & - & $.72 * *$ & $.88 * *$ & $.87 * *$ & $.38 * *$ & 21.22 & 5.12 & .87 \\
\hline 9 PFB-K quarreling & & & & & & & & - & $.43 * *$ & $.38 * *$ & $.19 * *$ & 7.22 & 1.79 & .72 \\
\hline 10 PFB-K togetherness & & & & & & & & & - & $.75^{* *}$ & $.33 * *$ & 7.03 & 1.95 & .71 \\
\hline 11 PFB-K tenderness & & & & & & & & & & - & $.42 * *$ & 6.96 & 2.29 & .89 \\
\hline 12 Sexual satisfaction & & & & & & & & & & & - & 3.81 & 1.10 & \\
\hline
\end{tabular}

MAAS, Mindful Attention Awareness Scale; CRSI, Conflict Resolution Style Inventory; conflict eng., conflict engagement; positive prob.sol, positive problem solving; IOS, Inclusion of Other in the Self; RAS, Relationship Assessment Scale; PFB-K, short form of Partnership Questionnaire

Partial correlations controlling for age, sex, education, immigrant background, relationship duration, marriage, and children. Variables 7-12 represent our dependent variables

$* p<.05, * * p<.01$

\section{Discussion}

The aim of the present study was to examine the relationship between trait mindfulness and partnership quality, partnership satisfaction, and sexual satisfaction, and in particular, to analyze the underlying processes of these associations. Destructive and positive conflict resolution styles as well as closeness in the partnership were assumed as mediators.

For two of the three partnership outcomes, the crosssectional association with mindfulness is mediated through the destructive conflict resolution style withdrawal (hypothesis 1). In none of our models did conflict engagement or compliance emerge as significant mediators. For positive problem solving, significant mediator effects were found between mindfulness and all relationship outcomes (hypothesis 2 ). The results of the mediation analyses only partly support hypothesis 3 . For one of the three partnership outcomes, interpersonal closeness proved to be a significant mediator of the mindfulness effects. In the other two cases, mediator effects fell short of significance. Thus, results of this study provide preliminary support for the theory that mindfulness contributes to positive partnership outcomes by enabling partners to be constructive when dealing with conflicts and simultaneously fostering feelings of closeness.

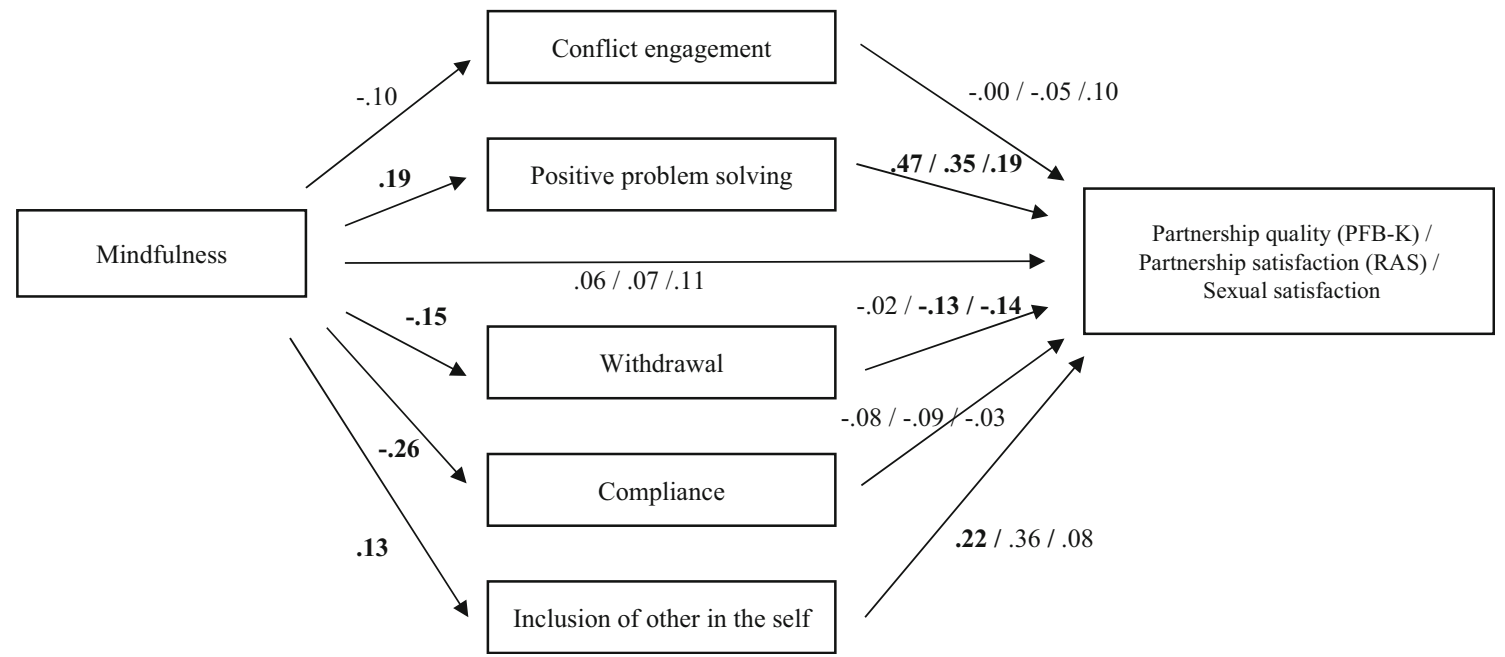

Fig. 1 Multiple mediation models of the relationship between mindfulness and partnership outcomes through conflict resolution styles and inclusion of the other in the self. Standardized b-coefficients from a bootstrap procedure are provided and bold values are significant $(p<.05)$. PFB-K short form of Partnership Questionnaire, RAS Relationship Assessment Scale 
The results of our study extend previous findings regarding the underlying processes between mindfulness and relationship outcomes. Research found that the ability to deal with anger plays a mediating role (Wachs and Cordova 2007). Mindful people seem better able to control their aggressive impulses and show less aggressive behavior such as hostility. In our study, however, of all destructive conflict resolution styles, only withdrawal behavior was a significant mediator between mindfulness and relationship outcomes. This finding leads to interesting conclusions. It seems particularly important not to withdraw from the relationship during conflict, but instead to stay in touch with the partner. Of all destructive styles, withdrawal is the one that temporarily breaks off the relationship, sends harmful nonverbal messages, and thus creates the greatest distance between partners (Noller et al. 2005). In contrast to showing such an indifferent attitude, conflict engagement and compliance at least convey the willingness to speak to the partner and to keep the lines of communication open. According to our results, it is not necessarily controlling aggression or being less compliant that is crucial for relationship outcomes, but above all, maintaining contact with the partner. The fact that a significant mediation emerged only for partnership satisfaction and sexual satisfaction as outcome variables and not for partnership quality might be due to our relatively small sample size. It is conceivable that with a higher power significant effects would have been found for all three outcome variables.

The focus in most studies on relationship outcomes so far has been on destructive interactions that were reduced by mindfulness. In contrast, we explicitly considered both negative and positive processes as possible mediators. Results of our study indicate that not only aggressive impulses might be better controlled by mindfulness, but also a conscious choice to act constructively in conflict situations is enabled. Findings indicate that mindfulness makes it more likely to stay in contact with the partner, to take their arguments into account, and to look for compromises, which has a positive effect on the relationship. Taken together, the positive processes seem to be the more relevant mediators between mindfulness and relationship outcomes. These findings align with prior studies that found stronger correlations of positive problem solving with partnership satisfaction than for the three destructive styles (Herzberg and Sierau 2010; Scheeren et al. 2014). The constructive and close atmosphere empowered by mindfulness contributes not only to more satisfaction with the partnership in general, but also to more sexual satisfaction. The significant association of positive conflict resolution with partnership outcomes was also emphasized in prior research that showed that constructive conflict strategies can reduce the negative effects of an insecure attachment style (Scheeren et al. 2014). Consequently, the authors consider positive conflict resolution as a protection factor for this association. Schneewind and Gerhard (2002) also emphasize constructive conflict resolution strategies as important aspects of a relationship and its further development. As conflict solving strategies develop into dispositional behavior patterns, the authors recommend working on positive skills as early as possible in a relationship.

Our study is amongst the first ones to pay attention to the association of mindfulness and interpersonal closeness. We found a significant mediation effect of closeness between mindfulness and partnership quality. For the other two indicators, coefficients fell just short of significance. These results thus provide first indications of a possible mediating role of closeness, which was also assumed by Trautwein et al. (2016). This finding also ties in with the mediating effect of withdrawal, which is interpreted as the maintenance of contact and closeness. Presumably, mindfulness conceptualized in this study as the ability to be present in the moment and acting with awareness enables partners to maintain close contact with one another both in everyday situations and in intimate interactions. When being mindful, one is less distracted by thoughts and rumination and can fully experience the present moment with the partner. This quality of experience may in turn contribute to greater satisfaction. However, given our relatively small sample size, the power of the study might have been insufficient to show a mediation effect in all three relationship outcomes.

The fact that the two positive processes, positive problem solving and closeness, proved to be relevant mediators is in line with Fruzzetti's argumentation (1996), since wellfunctioning relationships are characterized by these two characteristics and not primarily by the absence of negative interactions. Behaviors such as constructive discussions and active listening create an environment in which partners can disclose themselves and receive support and validation from each other (Fruzzetti 1996).

\section{Limitations and Future Directions}

There are several limitations to our study. First, the crosssectional correlational design of the study does not allow us to identify directions of causalities. The significant results do not necessarily mean that there is actually mediation but only that the data is consistent with the suspected model. Despite the theoretical derivation and justification of the assumed relationships, it cannot be ruled out that other mechanisms may play a role in our findings. Thus, future research should also consider alternative models and relations between the researched variables, for example, IOS being a dependent variable and partnership quality/satisfaction being possible mediators. In the context of multiple mediation models, the problem of intercorrelating scales must be considered. In parts, correlations occur between our mediators, though it would be an advantage if the mediators were to represent unique factors (Preacher and Hayes 2008). 
Second, this research is also limited by the composition of its sample since the sample was largely composed of women. Also, the educational level as well as the reported relationship quality of participants was relatively high, which may be due to self-selection effects and social desirability. Furthermore, a sample size of about 200 participants may be too low, especially for the identification of small effects (Fritz and MacKinnon 2007). Future research should use larger and more heterogenous samples to test our results and to examine the mediating role of closeness. In particular, the investigation of persons with relationship or sexual difficulties would be of great interest in this context.

Third, using an online questionnaire battery, this study relies solely on self-report measures which are prone to biases; e.g., McClelland (2011) criticizes self-reporting regarding sexual satisfaction. To obtain a more realistic view of the relationship outcomes, both partners should be recruited which would allow to calculate an averaged self and partner assessment. The assessment of couples could also help to identify actor and partner effects of mindfulness on relationship outcomes like sexuality. Future research should replicate these results and also longitudinally examine the effects of mindfulness on relationship outcomes, in order to draw not only correlational but also causal inferences.

Finally, there are also some limitations regarding our measures. Some authors criticize the unidimensional structure of the MAAS; e.g., the non-reactivity facet of mindfulness is not addressed. The dimension captured by the MAAS has the strongest correlations with the "acting with awareness" subscale of the FFMQ (Baer et al. 2006) which was of great interest in our study. Even if there are some major concerns about measuring mindfulness using self-report (e.g., Grossman 2008), all these scales still offer advantages and cannot be rejected as invalid (Bergomi et al. 2013). However, future research should also consider alternative measures of mindfulness. Our survey was embedded within a larger study resulting in a long questionnaire. Therefore, we have shortened the KSIP to keep participants motivated, though we have not tested the shortened version in a pilot study. Sexual satisfaction is a complex construct which should be measured with more detailed questionnaires; however, the use of singleitem measures for complex constructs may be an acceptable alternative (e.g., Cheung and Lucas 2014; Gogol et al. 2014). With our survey, brevity was a priority, as many participants might not have been willing to answer more intimate questions on their sexuality.

Our findings suggest that future research on mindfulness and partnership outcomes might benefit from assessing the role of positive conflict strategies. For instance, during mindfulness interventions such as the mindfulness-based relationship enhancement (Carson et al. 2004), progress measurements could also be made on the use of positive conflict resolution strategies. Such an approach may clarify whether an increase in mindfulness predicts more frequent use of positive conflict resolution, which in turn predicts better relationship outcomes. Future longitudinal studies could also better clarify the interplay of conflict resolution strategies and closeness. Feeling close to their partner, one probably communicates more constructively and positively instead of attacking or ignoring them. A positive climate in discussion and striving for compromise might also foster the feelings of closeness, so that these two mechanisms act together.

In sum, our study provides new insight into the effects of mindfulness on romantic relationships. The results suggest that it is predominantly the increase of positive processes (positive problem solving and closeness in the partnership) and to a lesser extent the decline of negative processes that contribute to a greater quality of relationship and satisfaction. The results of our study thus broaden our understanding of the processes that underlie fulfilling romantic relationships and in turn, underline the positive effects of mindfulness.

Author Contributions NG: designed and executed the study, analyzed the data, and wrote the paper. FN: consulted on the data analyses, collaborated in the writing and editing of the final manuscript. SS: collaborated with the design and in the writing of the study and the final manuscript. RS: prepared the study, consulted on the data analyses, collaborated in the writing and editing of the final manuscript. All authors approved the final version of the manuscript for submission.

Funding Information Open Access funding provided by Projekt DEAL.

\section{Compliance with Ethical Standards}

Conflict of Interest The authors declare that they have no conflict of interest.

Ethical Approval All procedures performed in studies involving human participants were in accordance with the ethical standards of the institutional and/or national research committee and with the 1964 Helsinki declaration and its later amendments or comparable ethical standards.

Open Access This article is licensed under a Creative Commons Attribution 4.0 International License, which permits use, sharing, adaptation, distribution and reproduction in any medium or format, as long as you give appropriate credit to the original author(s) and the source, provide a link to the Creative Commons licence, and indicate if changes were made. The images or other third party material in this article are included in the article's Creative Commons licence, unless indicated otherwise in a credit line to the material. If material is not included in the article's Creative Commons licence and your intended use is not permitted by statutory regulation or exceeds the permitted use, you will need to obtain permission directly from the copyright holder. To view a copy of this licence, visit http://creativecommons.org/licenses/by/4.0/.

\section{References}

Acker, M., \& Davis, M. H. (1992). Intimacy, passion and commitment in adult romantic relationships: a test of the triangular theory of love. Journal of Social and Personal Relationships, 9(1), 21-50. 
Adair, K. C., Boulton, A. J., \& Algoe, S. B. (2018a). The effect of mindfulness on relationship satisfaction via perceived responsiveness: findings from a dyadic study of heterosexual romantic partners. Mindfulness, 9, 597-609.

Adair, K. C., Fredrickson, B. L., Castro-Schilo, L., Kim, S., \& Sidberry, S. (2018b). Present with you: does cultivated mindfulness predict greater social connection through gains in decentering and reductions in negative emotions? Mindfulness, 9, 737-749.

Agnew, C.R., Loving, T. J., Le, B., \& Goodfriend, W. (2004). Thinking close: measuring relational closeness as perceived self-other inclusion. In D. J. Mashek \& A. P. Aron (Eds.), Handbook of closeness and intimacy (pp. 103-115). Lawrence Erlbaum Associates Publishers.

Aron, A., \& Aron, E. N. (1986). Love and the expansion of self: understanding attraction and satisfaction. Hemisphere Publishing Corporation.

Aron, A., Aron, E. N., \& Smollan, D. (1992). Inclusion of other in the self scale and the structure of interpersonal closeness. Journal of Personality and Social Psychology, 63(4), 596-612.

Aron, A., Aron, E. N., Tudor, M., \& Nelson, G. (1991). Close relationships as including other in the self. Journal of Personality and Social Psychology, 60(2), 241-253.

Aron, A., Lewandowski Jr, G. W., Mashek, D., \& Aron, E. N. (2013). The self-expansion model of motivation and cognition in close relationships. In J. Simpson \& L. Campbell (Eds.), The Oxford handbook of close relationships (pp. 90-115). Oxford University Press.

Askari, M., Noah, S. B. M., Hassan, S. A. B., \& Baba, M. B. (2012). Comparison the effects of communication and conflict resolution skills training on marital satisfaction. International Journal of Psychological Studies, 4(1), 182.

Atkinson, B. J. (2013). Mindfulness training and the cultivation of secure, satisfying couple relationships. Couple and Family Psychology: Research and Practice, 2(2), 73-94.

Baer, R. A., Smith, G. T., Hopkins, J., Krietemeyer, J., \& Toney, L. (2006). Using self-report assessment methods to explore facets of mindfulness. Assessment, 13(1), 27-45.

Barnes, S., Brown, K. W., Krusemark, E., Campbell, W. K., \& Rogge, R. D. (2007). The role of mindfulness in romantic relationship satisfaction and responses to relationship stress. Journal of Marital and Family Therapy, 33(4), 482-500.

Becker, B. D., Gallagher, K. C., \& Whitaker, R. C. (2017). Teachers' dispositional mindfulness and the quality of their relationships with children in head start classrooms. Journal of School Psychology, 65, 40-53.

Bergomi, C., Tschacher, W., \& Kupper, Z. (2013). The assessment of mindfulness with self-report measures: existing scales and open issues. Mindfulness, 4(3), 191-202.

Bihari, J. L. N., \& Mullan, E. G. (2014). Relating mindfully: a qualitative exploration of changes in relationships through mindfulness-based cognitive therapy. Mindfulness, 5(1), 46-59.

Brotto, L. A., \& Basson, R. (2014). Group mindfulness-based therapy significantly improves sexual desire in women. Behaviour Research and Therapy, 57, 43-54.

Brotto, L. A., Basson, R., Carlson, M., \& Zhu, C. (2013). Impact of an integrated mindfulness and cognitive behavioural treatment for provoked vestibulodynia (IMPROVED): a qualitative study. Sexual and Relationship Therapy, 28(1-2), 3-19.

Brotto, L. A., Erskine, Y., Carey, M., Ehlen, T., Finlayson, S., Heywood, M., Kwon, J., McAlpine, J., Stuart, G., Thomson, S., \& Miller, D. (2012a). A brief mindfulness-based cognitive behavioral intervention improves sexual functioning versus wait-list control in women treated for gynecologic cancer. Gynecologic Oncology, 125(2), $320-325$.

Brotto, L. A., Seal, B. N., \& Rellini, A. (2012b). Pilot study of a brief cognitive behavioral versus mindfulness-based intervention for women with sexual distress and a history of childhood sexual abuse. Journal of Sex \& Marital Therapy, 38(1), 1-27.

Brotto, L. A., \& Heiman, J. R. (2007). Mindfulness in sex therapy: applications for women with sexual difficulties following gynecologic cancer. Sexual and Relationship Therapy, 22(1), 3-11.

Burpee, L. C., \& Langer, E. J. (2005). Mindfulness and marital satisfaction. Journal of Adult Development, 12(1), 43-51.

Byers, E. S. (2005). Relationship satisfaction and sexual satisfaction: a longitudinal study of individuals in long-term relationships. The Journal of Sex Research, 42(2), 113-118.

Carson, J. W., Carson, K. M., Gil, K. M., \& Baucom, D. H. (2004). Mindfulness-based relationship enhancement. Behavior Therapy, 35(3), 471-494.

Chesney, A. F., Blakeney, P. E., Cole, C. M., \& Chan, F. A. (1981). A comparison of couples who have sought sex therapy with couples who have not. Journal of Sex \& Marital Therapy, 7(2), 131-140.

Cheung, F., \& Lucas, R. E. (2014). Assessing the validity of single-item life satisfaction measures: results from three large samples. Quality of Life Research, 23(10), 2809-2818.

Cordova, J. V., Jacobson, N. S., \& Christensen, A. (1998). Acceptance versus change interventions in behavioral couple therapy: impact on couples' in-session communication. Journal of Marital and Family Therapy, 24(4), 437-455.

Crespo, C., Davide, I. N., Costa, M. E., \& Fletcher, G. J. O. (2008). Family rituals in married couples: links with attachment, relationship quality, and closeness. Personal Relationships, 15(2), 191-203.

Cropley, C. J., \& Reid, S. A. (2008). A latent variable analysis of couple closeness, attributions, and relational satisfaction. The Family Journal, 16(4), 364-374.

Dinkel, A., \& Balck, F. (2005). An evaluation of the german relationship assessment scale. Swiss Journal of Psychology, 64(4), 259-263.

Fritz, M. S., \& MacKinnon, D. P. (2007). Required sample size to detect the mediated effect. Psychological Science, 18(3), 233-239.

Fruzzetti, A. E. (1996). Causes and consequences: individual distress in the context of couple interactions. Journal of Consulting and Clinical Psychology, 64(6), 1192-1201.

Fruzzetti, A. E., \& Iverson, K. M. (2004). Mindfulness, acceptance, validation, and "individual" psychopathology in couples. In S. C. Hayes, V. M. Follette, \& M. M. Linehan (Eds.), Mindfulness and acceptance: expanding the cognitive-behavioral tradition (pp. 168191). Guilford Press.

Fruzzetti, A. E., \& Jacobson, N. S. (1990). Toward a behavioral conceptualization of adult intimacy: implications for marital therapy. In E. A. Blechman (Ed.), Emotions and the family: for better or for worse (pp. 117-135). Erlbaum.

Gächter, S., Starmer, C., \& Tufano, F. (2015). Measuring the closeness of relationships: a comprehensive evaluation of the "inclusion of the other in the self" scale. PLoS One, 10(6), e0129478.

Gogol, K., Brunner, M., Goetz, T., Martin, R., Ugen, S., Keller, U., et al. (2014). "My questionnaire is too long!" The assessments of motivational-affective constructs with three-item and single-item measures. Contemporary Educational Psychology, 39(3), 188-205.

Gottman, J. M. (2014). What predicts divorce? The relationship between marital processes and marital outcomes. Erlbaum.

Grossman, P. (2008). On measuring mindfulness in psychosomatic and psychological research. Journal of Psychosomatic Research, 64(4), 405-408.

Hahlweg, K. (1996). Fragebogen zur Partnerschaftsdiagnostik (FPD). Hogrefe.

Hayes, A. F. (2013). Introduction to mediation, moderation, and conditional process analysis: A regression-based approach. The Guilford Press.

Heiman, J. R., Long, J. S., Smith, S. N., Fisher, W. A., Sand, M. S., \& Rosen, R. C. (2011). Sexual satisfaction and relationship happiness in midlife and older couples in five countries. Archives of Sexual Behavior, 40(4), 741-753. 
Hendrick, S. S. (1988). A generic measure of relationship satisfaction. Journal of Marriage and Family, 50(1), 93-98.

Herzberg, P. Y., \& Sierau, S. (2010). Das Konfliktlösungsstil-Inventar für Paare (KSIP). Diagnostica, 56(2), 94-107.

Iida, M., \& Shapiro, A. F. (2017). The role of mindfulness in daily relationship process: examining daily conflicts and relationship mood. Mindfulness, 8(6), 1559-1568.

Jose, O., \& Alfons, V. (2007). Do demographics affect marital satisfaction? Journal of Sex \& Marital Therapy, 33(1), 73-85.

Kabat-Zinn, J. (2009). Wherever you go, there you are: mindfulness meditation in everyday life. Hachette.

Kelley, T. M., \& Lambert, E. G. (2012). Mindfulness as a potential means of attenuating anger and aggression for prospective criminal justice professionals. Mindfulness, 3(4), 261-274.

Keng, S.-L., Smoski, M. J., \& Robins, C. J. (2011). Effects of mindfulness on psychological health: a review of empirical studies. Clinical Psychology Review, 31(6), 1041-1056.

Khaddouma, A., Gordon, K. C., \& Bolden, J. (2015). Zen and the art of sex: examining associations among mindfulness, sexual satisfaction, and relationship satisfaction in dating relationships. Sexual and Relationship Therapy, 30(2), 268-285.

Kliem, S., Job, A.-K., Kröger, C., Bodenmann, G., Stöbel-Richter, Y., Hahlweg, K., \& Brähler, E. (2012). Entwicklung und Normierung einer Kurzform des Partnerschaftsfragebogens (PFB-K) an einer repräsentativen deutschen Stichprobe. Zeitschrift für Klinische Psychologie und Psychotherapie, 41(2), 81-89.

Kurdek, L. A. (1994). Conflict resolution styles in gay, lesbian, heterosexual nonparent, and heterosexual parent couples. Journal of Marriage and Family, 56(3), 705-722.

Kurdek, L. A. (1995). Predicting change in marital satisfaction from husbands' and wives' conflict resolution styles. Journal of Marriage and Family, 57(1), 153-164.

Lakey, C. E., Kernis, M. H., Heppner, W. L., \& Lance, C. E. (2008). Individual differences in authenticity and mindfulness as predictors of verbal defensiveness. Journal of Research in Personality, 42(1), 230-238.

Le, B., Dove, N. L., Agnew, C. R., Korn, M. S., \& Mutso, A. A. (2010). Predicting nonmarital romantic relationship dissolution: a metaanalytic synthesis. Personal Relationships, 17(3), 377-390.

Lenger, K. A., Gordon, C. L., \& Nguyen, S. P. (2017). Intra-individual and cross-partner associations between the five facets of mindfulness and relationship satisfaction. Mindfulness, 8(1), 171-180.

MacKillop, J., \& Anderson, E. J. (2007). Further psychometric validation of the mindful attention awareness scale (MAAS). Journal of Psychopathology and Behavioral Assessment, 29(4), 289-293.

MacKinnon, D. P., Lockwood, C. M., \& Williams, J. (2004). Confidence limits for the indirect effect: distribution of the product and resampling methods. Multivariate Behavioral Research, 39(1), 99-128.

Mark, K. P., Herbenick, D., Fortenberry, J. D., Sanders, S., \& Reece, M. (2014). A psychometric comparison of three scales and a single-item measure to assess sexual satisfaction. Journal of Sex Research, 51(2), 159-169.

McCabe, M. P. (1997). Intimacy and quality of life among sexually dysfunctional men and women. Journal of Sex \& Marital Therapy, 23(4), 276-290.

McClelland, S. I. (2011). Who is the "self" in self reports of sexual satisfaction? Research and policy implications. Sexuality Research and Social Policy, 8(4), 304-320.

Medvedev, O. N., Siegert, R. J., Feng, X. J., Billington, D. R., Jang, J. Y., \& Krägeloh, C. U. (2016). Measuring trait mindfulness: how to improve the precision of the mindful attention awareness scale using a rasch model. Mindfulness, 7(2), 384-395.

Metz, M. E., \& Epstein, N. (2002). Assessing the role of relationship conflict in sexual dysfunction. Journal of Sex \& Marital Therapy, 28(2), 139-164.
Michalak, J., Heidenreich, T., Ströhle, G., \& Nachtigall, C. (2008). Die deutsche Version der Mindful Attention and Awareness Scale (MAAS). Psychometrische Befunde zu einem Achtsamkeitsfragebogen. Zeitschrift für Klinische Psychologie und Psychotherapie, 37(3), 200-208.

Muise, A., Kim, J. J., McNulty, J. K., \& Impett, E. A. (2016). The positive implications of sex for relationships. In C. Knee \& H. Reis (Eds.), Advances in personal relationships, Vol. 1: positive approaches to optimal relationship development (pp. 124-147). Cambridge University Press.

Newcombe, B. C., \& Weaver, A. D. (2016). Mindfulness, cognitive distraction, and sexual well-being in women. Canadian Journal of Human Sexuality, 25(2), 99-108.

Noller, P., Feeney, J. A., Roberts, N., \& Christensen, A. (2005). Nonverbal behavior in couple relationships: exploring the causes and consequences of withdrawal. In R. G. Riggio \& R. S. Feldman (Eds.), Applications of non-verbal communication (pp. 195-213). Erlbaum.

Paterson, L. Q. P., Handy, A. B., \& Brotto, L. A. (2017). A pilot study of eight-session mindfulness-based cognitive therapy adapted for women's sexual interest/arousal disorder. The Journal of Sex Research, 54(7), 850-861.

Pepping, C. A., Cronin, T. J., Lyons, A., \& Caldwell, J. G. (2018). The effects of mindfulness on sexual outcomes: the role of emotion regulation. Archives of Sexual Behavior, 47(6), 1601-1612.

Pepping, C. A., \& Halford, W. K. (2016). Mindfulness and couple relationships. In E. Shonin, W. Van Gordon, \& M. Griffiths (Eds.), Mindfulness and Buddhist-derived approaches in mental health and addiction (pp. 391-411) Springer International Publishing.

Preacher, K. J., \& Hayes, A. F. (2008). Asymptotic and resampling strategies for assessing and comparing indirect effects in multiple mediator models. Behavior Research Methods, 40(3), 879-891.

Pruitt, I. T., \& McCollum, E. E. (2010). Voices of experienced meditators: the impact of meditation practice on intimate relationships. Contemporary Family Therapy, 32(2), 135-154.

Quaglia, J. T., Goodman, R. J., \& Brown, K. W. (2015). From mindful attention to social connection: the key role of emotion regulation. Cognition \& Emotion, 29(8), 1466-1474.

Rosenheim, E., \& Neumann, M. (1981). Personality characteristics of sexually dysfunctioning males and their wives. The Journal of Sex Research, 17(2), 124-138.

Rubin, H., \& Campbell, L. (2012). Day-to-day changes in intimacy predict heightened relationship passion, sexual occurrence, and sexual satisfaction: a dyadic diary analysis. Social Psychological and Personality Science, 3(2), 224-231.

Sánchez-Fuentes, M. M., Santos-Iglesias, P., \& Sierra, J. C. (2014). A systematic review of sexual satisfaction. International Journal of Clinical and Health Psychology, 14(1), 67-75.

Scheeren, P., Vieira, R. V. A., Goulart, V. R., \& Wagner, A. (2014). Marital quality and attachment: the mediator role of conflict resolution styles. Paidéia (Ribeirão Preto), 24(58), 177-186.

Schenk, J., Pfrang, H., \& Rausche, A. (1983). Personality traits versus the quality of the marital relationship as the determinant of marital sexuality. Archives of Sexual Behavior, 12(1), 31-42.

Schneewind, K. A., \& Gerhard, A.-K. (2002). Relationship personality, conflict resolution, and marital satisfaction in the first 5 years of marriage. Family Relations, 51(1), 63-71.

Segrin, C., Hanzal, A., \& Domschke, T. J. (2009). Accuracy and bias in newlywed couples' perceptions of conflict styles and the association with marital satisfaction. Communication Monographs, 76(2), 207233.

Shafer, K., Jensen, T. M., \& Larson, J. H. (2014). An actor-partner model of relationship effort and marital quality. Family Relations, 63, 654 666.

Smith, A. M. A., Patrick, K., Heywood, W., Pitts, M. K., Richters, J., Shelley, J. M., Simpson, J. M., \& Ryall, R. (2012). Body mass 
index, sexual difficulties and sexual satisfaction among people in regular heterosexual relationships: a population-based study. Internal Medicine Journal, 42, 641-651.

Snyder, D. K. (1979). Multidimensional assessment of marital satisfaction. Journal of Marriage and Family, 41(4), 813-823.

Stanley, S. M., Markman, H. J., \& Whitton, S. W. (2002). Communication, conflict, and commitment: insights on the foundations of relationship success from a national survey. Family Process, 41(4), 659-675.

Trautwein, F.-M., Naranjo, J. R., \& Schmidt, S. (2014). Meditation effects in the social domain: self-other connectedness as a general mechanism? In S. Schmidt \& H. Walach (Eds.), Meditation - neuroscientific approaches and philosophical implications (pp. 175198). Springer International Publishing.

Trautwein, F.-M., Naranjo, J. R., \& Schmidt, S. (2016). Decentering the self? Reduced bias in self- vs. other-related processing in long-term practitioners of loving-kindness meditation. Frontiers in Psychology, 7, 1785.

Twenge, J. M., Campbell, W. K., \& Foster, C. A. (2003). Parenthood and marital satisfaction: a meta-analytic review. Journal of Marriage and Family, 65(3), 574-583.
Wachs, K., \& Cordova, J. V. (2007). Mindful relating: exploring mindfulness and emotion repertoires in intimate relationships. Journal of Marital and Family Therapy, 33(4), 464-481.

Way, B. M., David, J., Eisenberger, N. I., \& Lieberman, M. D. (2010). Dispositional mindfulness and depressive symptomatology: correlations with limbic and self-referential neural activity during rest. Emotion, 10(1), 12-24.

Weidler, D. J., \& Clark, E. M. (2011). A distinct association: inclusion of other in the self and self-disclosure. The New School Psychology Bulletin, 9(1), 36-46.

Yeh, H.-C., Lorenz, F. O., Wickrama, K. A. S., Conger, R. D., \& Elder Jr., G. H. (2006). Relationships among sexual satisfaction, marital quality, and marital instability at midlife. Journal of Family Psychology, 20(2), 339-343.

Publisher's Note Springer Nature remains neutral with regard to jurisdictional claims in published maps and institutional affiliations. 